\title{
Making a Difference: Education at the 10th International Conference on Zebrafish Development and Genetics
}

\author{
Lara D. Hutson, Jennifer O. Liang, ${ }^{2}$ Michael A. Pickart, ${ }^{3}$ \\ Chris Pierret, ${ }^{4}$ and Henry G. Tomasciewicz ${ }^{5}$
}

\begin{abstract}
Scientists, educators, and students met at the 10th International Conference on Zebrafish Development and Genetics during the 2-day Education Workshop, chaired by Dr. Jennifer Liang and supported in part by the Genetics Society of America. The goal of the workshop was to share expertise, to discuss the challenges faced when using zebrafish in the classroom, and to articulate goals for expanding the impact of zebrafish in education.
\end{abstract}

\section{Introduction}

W HEN RESEARCHERS CONVERGED on Madison this year at the 10th International Conference on Zebrafish Development and Genetics, a number of them, along with a contingent of teachers, administrators, and students, met over the course of two sessions of the "Zebrafish in Education" Workshop. The zebrafish system has great potential to impact learning in a wide range of fields, including, but not limited to, developmental biology, genetics, evolutionary biology, toxicology, environmental science, disease mechanisms, drug development, and genetic engineering. Many groups throughout the world have begun using zebrafish in a wide variety of ways to facilitate $\mathrm{K}-12$ and undergraduate learning. A major goal of this workshop was to encourage these individuals to share their expertise and experience, to discuss the challenges that they face, and to collectively formulate a plan for expanding the impact of zebrafish in education. In addition, Aquaneering Inc., one of the major suppliers of zebrafish racks for research, announced the generous donation of two of their new E-racks (stand-alone fish racks scaled down for use in educational settings) to K-12 teachers who could demonstrate the need for a stable multi-tank system in order to facilitate use of zebrafish in their classrooms. These racks, plus one additional rack, were recently awarded in a competitive review process.

\section{Existing Programs Expand the Breadth and Depth of Educational Programs Using Zebrafish}

The first session of the Education Workshop focused on the wide variety of outreach programs currently in existence, and ways in which assessment can be used to improve and measure the effects we are having on student learning and attitudes about science.

BioEYES, which originated as a tool to teach genetics, was the first outreach program to employ zebrafish broadly in the $\mathrm{K}-12$ classroom and is a model for many programs today. ${ }^{1}$ BioEYES founder Steve Farber of the Carnegie Institution for Science gave an update on the program, noting that as of this year BioEYES, which is active in Philadelphia, Baltimore, South Bend (IN), and several other cities, will have reached over 70,000 students in grades $\mathrm{K}-12$. The genetics component of BioEYES continues, and the Baltimore program has added an extensive module in Environmental Science to enhance learning about the Chesapeake Bay watershed. Dr. Farber also described some highlights of assessment data they have acquired over the years. Perhaps the most striking among these was the finding that students' attitudes about science crystallize by the time they reach high school, and not necessarily for the better. This observation highlights the importance of exposing students to hands-on science earlier, during elementary and middle school. Fortunately, many of the

\footnotetext{
${ }^{1}$ Department of Biological Sciences, University at Buffalo, Buffalo, New York.

${ }^{2}$ Department of Biology, University of Minnesota Duluth, Duluth, Minnesota.

${ }^{3}$ School of Pharmacy, Concordia University Wisconsin, Mequon, Wisconsin.

${ }^{4}$ Department of Biochemistry and Molecular Biology, Mayo Clinic, Rochester, Minnesota.

${ }^{5}$ Great Lakes WATER Institute, University of Wisconsin-Milwaukee, Milwaukee, Wisconsin.
} 
programs discussed throughout these sessions target students in middle school and younger.

Among these, Integrated Science Education Outreach (InSciEd Out), a collaboration between the Mayo Clinic, Winona State University, and the Rochester (MN) Public Schools, is an exciting newer program. Jim Sonju, Principal of Lincoln K-8 Choice School, described the program. During the past 3 summers, InSciEd Out has brought in every single teacher from a selected grade level for a comprehensive science internship. This internship is followed by support for classroom implementation of ideas borne out of the internship. One of the foremost challenges associated with using zebrafish in a $\mathrm{K}-12$ classroom is, not surprisingly, housing, and one of the most useful ideas to date from this collaboration is a simplified fish rack with adaptations for raising embryos which allows teachers to implement hands-on zebrafish experiments in their classrooms. ${ }^{2}$ While this program does not exclusively employ zebrafish in all of its science modules, zebrafish are clearly one of its greatest strengths.

Summer internships for teachers was a common theme among outreach programs. Another program employing this model was developed by Henry Tomasiewicz and colleagues of the University of Wisconsin, Milwaukee, as one module of a larger Science Education Partnership Award program. In this module, high school teachers attend an intensive weeklong workshop in university labs where they are trained to use zebrafish as a model system to study various aspects of Environmental Health Sciences. Teachers are then given extensive support to set up aquaria in their classroom, where students eventually perform experiments analyzing the effects of caffeine, nicotine, alcohol, and toxicants of their choosing on zebrafish embryos. Students are then required to write manuscripts and participate in a manuscript review process. Importantly, both teachers and students provide feedback as to how the modules have affected their view of science generally and the life sciences specifically. In only the second year, this evaluation process has already led to an improvement in the implementation of the teaching modules that comprise this program. This approach capitalizes on students' natural curiosity about how their environment directly affects them. It is also hoped that hands-on experience with the detrimental effects of nicotine and alcohol may delay students' use of substances of abuse.

A similar program, an Interdisciplinary Science and Engineering Partnership (ISEP) between University at Buffalo, Buffalo State University, and the Buffalo Public Schools (NY), was then described by Lara Hutson of the University at Buffalo. The graduation rate in the Buffalo Public Schools is approximately $54 \%$, and millions of dollars in funds are in jeopardy due to political deadlock between the teachers' union and the school district. The ISEP program, which was established by Dr. Joe Gardella in the Department of Chemistry at the University at Buffalo, aims to transform STEM education in the schools and to provide continuity regardless of the political climate. This program hosts as many as 60 high school and middle school teachers from Buffalo schools every summer to work in research laboratories. In collaboration with laboratory directors and graduate students, these teachers are then tasked with developing curricular innovations for their classrooms based on the materials, tools, and approaches to which they are exposed during the summer. Each of the schools then receives the support of at least one full-time graduate student and sufficient funding to purchase the materials needed to help implement the curricula.

While the Buffalo Public School system may be troubled, their challenges are perhaps not as great as those faced by Dr. Kathleen Whitlock of the Center for Neuroscience at the University of Valparaiso, Chile, where poverty is widespread and the narcotics trade is pervasive. Chile has the largest gap between the highest- and lowest-performing schools in Latin America, and this gap is strongly correlated with socioeconomic level. Dr. Whitock described an outreach program she developed in 2008 called "Ciencia Al Tiro" —or "Science Immediately" - to address the inequalities in public education by helping low-income public schools in the local community, Cerro Playa Ancha. Dr. Whitlock and graduate students at the center designed 24 different workshops, some of which involve zebrafish, to use in the local schools. The workshops are designed so that students get to participate in hands-on science within 10 minutes of the beginning of instruction, thus maximizing the time spent doing and minimizing the time spent listening. This program is now operating in two schools, and there are plans for expansion.

Melanie Fields also described her ongoing program with students at Sidwell Friends School in Washington, D.C., using zebrafish in her Neuroscience class. Mrs. Fields' students have been successful over the years at taking on exceptionally challenging projects, in some cases, following through with presentation at major scientific conferences as well as participation in peer-review and publication. ${ }^{3}$ In their talk, Sidwell students Aiyana Riddihough, Melissa Lu, Anna Hoover, Anna Johnson, and Nina Campbell also illuminated one possible solution to the perennial challenge of finding 7-daya-week caretakers for classroom fish, stating that in Mrs. Fields' classroom, all of the students share responsibility for care of the fish. Furthermore, because it is common to find students working on their experiments after school and on weekends, caretakers during these times are readily available.

Zebrafish are also proving useful for collaborative research and discovery based activities across grade levels through the Portals of Discovery Project (PODS), ${ }^{4}$ an NSF funded project to create collaborative research pipelines linking primarily high schools, two-, and four-year colleges and universities in Wisconsin. Michael Pickart (Concordia University Wisconsin and previously UW-Stout) described briefly the important capacity of zebrafish to focus students on broad and meaningful research projects, for example, through his participation in an ongoing PODS natural products drug discovery project with Kitrina Carlson (UW-Stout), Rebecca Abler (UWManitowoc), Richard Hein (UW-Manitowoc), and Manitowoc area high school teachers, and students from Lincoln and Valders High Schools. However, he also noted that establishing zebrafish and other resources to carry out research among all the partners is still challenging, despite the many advantages of zebrafish.

Several additional new programs were also described by attendees at the meeting. Alexis Webb, now of the Max Planck Institute of Molecular Cell Biology and Genetics in Dresden, Germany, spoke about her work on a collaborative program between Washington University and the St. Louis Science Center that trained graduate students in how to communicate information about science and scientists to the general public. ${ }^{5}$ Nathalia Holtzman, of the City University of New York, and Martha Marvin, of Williams College in Williamstown, 
Massachusetts, also described programs they are developing for their local schools.

\section{Challenges, Solutions, and Plans for Increasing the Impact of Zebrafish on Science Education}

Students and teachers attending the Education Workshop stressed the impact that the zebrafish community can potentially have on the development of new scientists by making the zebrafish meeting open and accessible. The Genetics Society of America, the sponsor of this year's meeting, strongly supported this goal, offering reduced registration costs to $\mathrm{K}-12$ teachers and students. This reduced cost was instrumental in enabling 45 members of the InSciEd Out program, including students, teachers, parents, and professional scientists, to attend. Mrs. Fields emphasized that the continued support of the research community, particularly scientific societies, should be a high priority to ensure that students continue to be provided with opportunities to present at conferences, a quintessential aspect of the scientific process. Students from Sidwell Friends School reiterated this need, expressing their gratitude to the scientists who have made their work possible, and expressing the hope that that the support continues. Making zebrafish meetings open to students and educators will be a continuing goal.

Another demonstrated way to increase access of students to basic science came from students who have taken on the responsibility to mentor younger students. Michael Ekker, Gregory Nathan, Xiuqi Cao, and Charlie Enriquez-Sarano, student representatives from Century High School in Rochester, MN, described their school's Science Technology Engineering and Math (STEM) Society, which was established by students with a common interest in providing independent, hands-on research opportunities for students in their own school as well as to motivate younger students to become interested in science. ${ }^{6}$ The Sidwell students also highlighted the fact that the openness of Mrs. Fields research classroom allows for more-experienced students to mentor those who are less experienced with fish husbandry, research, or both. This model can be difficult to emulate, but it is clearly worth the effort, particularly as older peers can serve as excellent role models.

Some of the most exciting and thought-provoking discussions arose from the STEM Society's presentation, including their use of virtual meetings to get around the problem of busy schedules, the use of social media to keep each other informed, and the prospect of an official charter that could be used by students at other schools who are interested in setting up their own societies. Together, these tools could enable like-minded middle school and high school students throughout the world to get involved, share ideas, and potentially collaborate on science and related endeavors. Out of this discussion came a plan, still in progress, to create a social media site that will provide links and guidance to all of the websites that are building tools for using zebrafish in educational efforts.

Another challenge the zebrafish educational community faces is continuing to share materials and expertise as the community grows. Typically, resources are gathered and willingly shared by individual laboratories. However, this has the disadvantage of placing the burden for distribution on the researchers themselves. In addition, these resources may require extensive tailoring to make them suitable for use by students at home, in the field, or in sparsely equipped school science labs. A potential model to address these issues was presented by Michael Pickart of Concordia University Wisconsin. He described efforts to establish TechToolWorks (TTW), a nonprofit organization dedicated to the development of affordable, stand-alone science kits specifically designed for education through academic and business partnerships with TTW. For example, through efforts of students at UW-Stout, including Lance Gregorich, Gerrick Meyer, Veronica Smith, and Sara Gregorich, as well as business partner Ken Smith, TTW has worked with primarily middle school teachers and students to develop a stand-alone kit and associated learning activities focused on DNA biochemistry and DNA diagnostic techniques. Without the specific focus by the TTW research and development team to bring this particular technology to a middle school classroom, the burden would have been on middle school teachers and likely not ever attempted. Thus, the capacity of the TTW model to adapt state-of-the-art technology for science education, including tools for zebrafish research, fills an important gap for the sharing of resources and bringing cutting edge technology to the classroom.

\section{Publication}

Another mechanism to expand the reach of zebrafish science is through publication, and the challenges we face were articulated by Jennifer Liang of University of Minnesota, Duluth. Ideally, we would like to see a central repository for publication of zebrafish-specific education manuscripts, including manuscripts on teaching tools and curricula and manuscripts reporting original research by $\mathrm{K}-16$ students. There is already an excellent existing venue for publishing peer-reviewed educational manuscripts in the journal Zebrafish, which grew out of discussions in a previous Education Workshop and support from Zebrafish Editor-in-Chief Dr. Steve Ekker. ${ }^{7}$ However, publication costs and limited open access options potentially restrict the reach of this approach. Unfortunately, there are no other existing journals that fit all of the education-related research being done by the zebrafish community. For instance, there are many excellent journals for publishing student research, but these would not be appropriate for articles on new curricula. Participants discussed various alternative models for publication, including the establishment of a nonprofit organization specifically dedicated to publishing zebrafish articles, piggy-backing on an existing nonprofit organization, or continuing to operate within the confines of the existing options.

A model for mentoring students through the process of publishing their research was articulated by Linnea Archer, an English teacher at Lincoln K-8 Choice School (MN). Ms. Archer has attained a goal that few teachers at any level have- $100 \%$ student participation in manuscript preparation and peer review. Students in Ms. Archer's class work collaboratively to prepare manuscripts based on research performed during science classes, subsequently submitting them for review using Next Generation Paper (NGP), a revolutionary software tool designed by David Argue at the Mayo Clinic. NGP allows for complete online submission, review, revision, publication, and viewing of completed manuscripts. Having her students work collaboratively on manuscript preparation capitalizes on their diverse talents, allowing not only students who are particularly skilled in science, but also 
those whose talents lie in writing, literature review, and graphic design to participate more fully, hopefully enhancing their enjoyment and thus understanding of the science itself. The NGP interface is actively being piloted in the 2012-2013 academic year with Lincoln and partner schools. Those who would like to take part in this pilot can contact Chris Pierret at pierret.christopher@mayo.edu. The InSciEd Out team has set the goal of sharing the format more fully at the 2013 Midwest Zebrafish Meeting in Milwaukee.

The work by Ms. Archer and her students suggest a way that the zebrafish community could expand their impact by serving as a central resource for increasing the opportunity for students to publish their original research. This publication program has great potential for broad application, extending beyond a single institution and providing an interface that connects the community of scientists from K-throughemeritus. Articles produced within their schools could be used as a springboard for those interested in preparing their work for publication in a peer-reviewed journal. Efforts to implement this plan are under way.

\section{Summary}

In order to make a meaningful difference in the education of rising scientists and citizens, we must continue to share expertise and collaborate within the zebrafish education community-which can now count researchers, teachers, administrators, and students among its members-but we must also continue to broaden our impact beyond the existing community. This workshop provided scientists and educators with information about a variety of different models for outreach and a fruitful discussion about their progress and pitfalls. This sharing of expertise, combined with the articulation of specific goals for the community, will likely contribute substantially towards our efforts to make a difference in science education.

\section{Disclosure Statement}

No competing financial interests exist.

\section{References}

1. Shuda J, Kearns-Sixsmith D. Outreach: Empowering students and teachers to fish outside the box. Zebrafish 2009;6:133-138. Available at http://www.bioeyes.org.

2. Panetta $M$, Thammavong L, Fredricksen $H$, Jama M, Yenew $\mathrm{K}$, Goodnow $\mathrm{G}$, et al. A highly accessible classroom aquaculture rig. Zebrafish 2012;9:195-199.

3. Fields MC, Adelfio P, Ahmad D, Brown O, Cox B, Davies M, et al. Danio rerio in $\mathrm{K}-12$ classrooms: Sparking interest in the new generation of scientists. Zebrafish 2009;6:145-60.

4. Portals of Discovery Project. Available at http://www.portals ofdiscovery.org and http://www3.uwstout.edu/faculty/ carlsonki/nsfportals.cfm, accessed December 6, 2012.

5. Webb $A B$, Fetsch $C R$, Israel E, Roman $C M$, Encarnacion $\mathrm{CH}$, Zacks JM, et al. Training scientists in a science center improves science communication to the public. Adv Physiol Educ 2012;36:72-76.

6. Ekker MP, Nathan GJ, Cao X, Enriquez-Sarano C. STEM Lab: Open lab for novel, student-led science exploration in the public schools. Zebrafish 2012;9:250 [abst].

7. Barresi MJ, Farber SA, Hutson LD, Hyde DR, Liang JO, Morris JK. Zebrafish in the Classroom. Zebrafish 2009;5: 205-208.
Address correspondence to: Lara D. Hutson, Ph.D. Department of Biological Sciences State University of New York at Buffalo 109 Cooke Hall Buffalo, NY 14260

E-mail: larahuts@buffalo.edu 